Hematol Oncol Clin North Am. 2012 June ; 26(3): 589-605. doi:10.1016/j.hoc.2012.02.001.

\title{
Tyrosine Kinase Inhibitors in Lung Cancer
}

\author{
Anish Thomas, Arun Rajan, and Giuseppe Giaccone \\ National Cancer Institute, Bethesda, Maryland, USA
}

\section{SYNOPSIS}

'Driver mutations' are essential for carcinogenesis as well as tumor progression as they confer a selective growth advantage to cancer cells. Identification of driver mutations in growth related protein kinases, especially tyrosine kinases have led to clinical development of an array of tyrosine kinase inhibitors in various malignancies, including lung cancer. Inhibition of epidermal growth factor receptor and anaplastic lymphoma kinase tyrosine kinases have proven to be of meaningful clinical benefit, while inhibition of several other tyrosine kinases have been of limited clinical benefit, thus far. An improved understanding of tyrosine kinase biology has also led to faster drug development, identification of resistance mechanisms and ways to overcome resistance. In this review, we discuss the clinical data supporting the use and practical aspects of management of patients on epidermal growth factor receptor and anaplastic lymphoma kinase tyrosine kinase inhibitors.

\section{Keywords}

Non-small cell lung cancer; tyrosine kinase inhibitor; epidermal growth factor receptor; ALKtranslocation; Vascular endothelial growth factor

\section{INTRODUCTION}

Lung cancer accounts for more deaths than any other cancer in both men and women in the USA and worldwide. ${ }^{1-2}$ Non-small cell lung cancer (NSCLC) constitutes approximately $85 \%$ of all lung cancers and forty percent of patients with newly diagnosed NSCLC have metastatic disease. ${ }^{1}$ In patients with advanced NSCLC, as well as those who relapse after initial definitive therapy, platinum based systemic chemotherapy improves survival, quality of life and symptom control compared with supportive care. ${ }^{3}$ However, despite the addition of new therapies, the median overall survival of patients with advanced NSCLC is approximately 1 year and only $3.5 \%$ of patients survive 5 years after diagnosis. ${ }^{4}$

Protein kinases play a crucial role in signal transduction, cellular proliferation, differentiation and other regulatory mechanisms. The identification of growth related protein

\footnotetext{
Address for correspondence: Giuseppe Giaccone, M.D., Ph.D., National Cancer Institute, Room 12N226, 10 Center Drive, Bethesda, MD 20892. Phone: 301-496-4916; Fax: 301-402-0172; giacconeg@ mail.nih.gov.

Anish Thomas, M.D., National Cancer Institute, Room 12N226, 10 Center Drive, Bethesda, MD 20892. Phone: 301-496-4916; Fax: 301-402-0172; anish.thomas@ nih.gov

Arun Rajan, M.D., National Cancer Institute, Room 12N226, 10 Center Drive, Bethesda, MD 20892. Phone: 301-496-4916; Fax: 301-402-0172; rajana@ nih.gov

Publisher's Disclaimer: This is a PDF file of an unedited manuscript that has been accepted for publication. As a service to our customers we are providing this early version of the manuscript. The manuscript will undergo copyediting, typesetting, and review of the resulting proof before it is published in its final citable form. Please note that during the production process errors may be discovered which could affect the content, and all legal disclaimers that apply to the journal pertain.

Financial disclosure and conflict of interest: None
} 
kinases, especially tyrosine kinases as a therapeutic target for cancer and ATP-binding domain of tyrosine kinases as an attractive target for drug design have led to clinical development of an array of tyrosine kinase inhibitors in various malignancies, including lung cancer. In recent years, clinical application of these agents coupled with understanding of NSCLC as a heterogeneous disease with several genetic subsets, has led to median survival extending over 30 months in selected patients with advanced NSCLC. ${ }^{5}$ In this review, we will discuss tyrosine kinase inhibitors in lung cancer. We focus on clinical evidence supporting the use and practical aspects of management of patients using inhibitors of two of the most extensively studied tyrosine kinases in recent past: epidermal growth factor receptor (EGFR) and anaplastic lymphoma kinase (ALK).

\section{EPIDERMAL GROWTH FACTOR RECEPTOR TYROSINE KINASE INHIBITORS}

EGFR (HER1, ErbB1) is the member of a family of trans-membrane glycoprotein receptors that also includes HER2, HER3 and HER4 (also known as ERBB2, 3 and 4 respectively). In normal cells, ligand binding to extracellular domain of EGFR induces receptor homo and heterodimerization which leads to conformational changes in EGFR, activation of the intracellular tyrosine kinase domain, phosphorylation of specific tyrosine residues and recruitment of a range of proteins which activates downstream signaling pathways including mitogen-activated protein kinase (MAPK), phosphatidylinositol-3-OH kinase (PI3K/Akt), and the signal transducer and activator of transcription (STAT)-mediated pathways. In NSCLC, EGFR protein is expressed in 50-90\% of cases and EGFR associated signaling pathways are frequently dysregulated. ${ }^{6-7}$ The two major approaches to EGFR inhibition are the use of small-molecule inhibitors of intracellular tyrosine kinase domain and monoclonal antibodies, which block the extracellular domain of the receptor. Gefitinib and erlotinib are orally administered EGFR-tyrosine kinase inhibitors, which compete with ATP for binding to the tyrosine-kinase domain.

\section{Clinical trials of EGFR-tyrosine kinase inhibitors in lung cancer}

Results of initial phase II studies of EGFR TKI's in previously treated patients with advanced NSCLC of all histologies appeared very promising. IDEAL 1 and 2, both randomized, double-blind, phase II, multicenter trials, which evaluated $250 \mathrm{mg}$ or $500 \mathrm{mg}$ of continuous oral gefitinib in more than 400 patients, demonstrated tumor objective response rates (ORR) of 9-19\%, median survival of 6-8 months and improvement in lung cancer symptoms. ${ }^{8-9}$ There was no difference in ORR, time to progression and median survival between the two doses and the $500 \mathrm{mg}$ dose level was associated with more adverse events. In May 2003, based on data from IDEAL 2 trial, gefitinib $(250 \mathrm{mg})$ received accelerated approval by the U.S. Food and Drug Administration (FDA) for monotherapy of patients with advanced NSCLC after failure of both platinum-based chemotherapy and docetaxel. A smaller phase II trial of continuous oral erlotinib in 57 patients also showed response rates of $12.3 \%$, median survival of 8.4 months and tumor related symptom improvement. ${ }^{10}$

However, in previously untreated patients with advanced NSCLC of all histologies, randomized trials of combination of EGFR-tyrosine kinase inhibitors with conventional chemotherapy showed no improvements in overall survival over chemotherapy alone. ${ }^{11-14}$ INTACT 1 and INTACT 2 trials demonstrated no survival benefit of concurrent administration of gefitinib with either cisplatin/gemcitabine or carboplatin/paclitaxel, respectively, compared to chemotherapy alone. ${ }^{11-12}$ Similarly, TALENT and TRIBUTE trials which combined erlotinib with cisplatin/gemcitabine or carboplatin/paclitaxel, respectively, showed no survival benefit compared to chemotherapy alone. ${ }^{13-14}$ 
In chemotherapy pre-treated NSCLC patients, two large multicenter phase III trials which evaluated monotherapy with EGFR-tyrosine kinase inhibitors, yielded divergent results. ${ }^{15-16}$ The BR.21 trial randomized 731 patients with all histologies of advanced NSCLC who had received one or two prior chemotherapy regimens in a 2:1 ratio to receive either erlotinib or placebo. ${ }^{16}$ Despite a high proportion of patients who had received two or more prior chemotherapies (50\%), overall survival, the primary endpoint of the study (6.7 months vs. 4.7 months; HR, 0.70; $<<0.001)$, ORR $(8.9 \%$ vs. $<1 \%$; p <0.001) and improvements in symptoms favored the erlotinib group. In contrast, a similarly designed ISEL trial of 1692 patients found no significant survival advantage for gefitinib either in the overall population of NSCLC patients who had received one or two prior chemotherapy regimens or in the adenocarcinoma co-primary population. ${ }^{15}$ Although the two trial populations were similar in many respects, a higher proportion of ISEL trial population had not responded to prior chemotherapy regimen (38\% vs.18\%) and had progressive disease ( $45 \%$ vs. $28 \%$ ) compared with the BR.21 population. Another possible explanation of the discordant results was the relatively low drug dosing in ISEL trial, which used one third the maximum tolerated dose (MTD) of gefitinib $(250 \mathrm{mg}$ ) compared to the MTD of erlotinib $(150 \mathrm{mg})$ which was used in the BR.21 trial. As a result of these post-marketing phase III results, in 2005, U.S. FDA restricted the use of gefitinib to patients who are currently benefiting or have previously benefited from its use.

In selected chemo-naive patients with advanced NSCLC, five phase III open label, randomized trials in East Asian patients demonstrated the superior objective response rate (ORR) and progression free survival (PFS) when gefitinib was compared with platinum based chemotherapy. ${ }^{5,17-20}$ The IPASS and First- SIGNAL trial populations were enriched to increase the likelihood of response based on clinico-pathologic features, i.e. never/former light smokers and adenocarcinoma histology. ${ }^{17,}{ }^{19}$ OPTIMAL, WJTOG3405 and NEJ002 trial populations were molecularly defined based on the presence of EGFR activating mutations and additionally in case of NEJ002, absence of a resistant mutation. ${ }^{5,18,20}$ IPASS which was the largest of these trials, was designed with PFS as the primary end point to assess the non-inferiority of gefitinib compared with carboplatin/paclitaxel in 1217 patients. ${ }^{17}$ The study met its primary objective of demonstrating non-inferiority and showed superiority of gefitinib for PFS (HR 0.74; 95\%CI, 0.65-0.85; p<0.001), ORR (43\% vs. $32.2 \% ; \mathrm{p}<0.001)$ and quality of life in the overall study population. ${ }^{17}$ Recently reported updated survival results showed no significant difference in overall survival between the treatment arms in the intention-to-treat population (HR 0.90; 95\% CI 0.79-1.02; $\mathrm{p}=0.109$ ) as well as in the mutation positive and negative subgroups. ${ }^{21}$ One of the factors which possibly contributed to the lack of survival benefit is the high proportion of patients in the chemotherapy arm (64.3\%) who received gefitinib at progression. Results of EURTAC, a phase III randomized study which compared erlotinib with platinum based chemotherapy in chemo-naive Caucasian patients with EGFR activating mutations also reported a PFS (9.4 months vs. 5.2 months; HR $0.42 ; \mathrm{p}<0.0001$ ), but no overall survival benefit of erlotinib. ${ }^{22}$

In the maintenance setting, several phase III trials have demonstrated modest improvements in PFS, but no OS advantage with gefitinib ${ }^{23-24}$ or erlotinib ${ }^{25-27}$ after chemotherapy in unselected patients with advanced NSCLC. In the SATURN study $(n=884)$, erlotinib prolonged PFS in patients who had non-progressive disease after four cycles of first-line platinum doublet chemotherapy in the overall population as well as in the EGFR immunohistochemistry (IHC) positive subgroups. After a median follow-up over 11 months, median PFS was longer with erlotinib than with placebo [12.3 weeks vs. 11.1 weeks (HR $0.71,95 \%$ CI $0 \cdot 62-0 \cdot 82 ; \mathrm{p}<0.0001)] .{ }^{25}$ In a prospectively planned analysis of the SATURN study, OS was significantly prolonged with maintenance erlotinib, compared with placebo (HR $=0.72$ [95\% CI 0.59-0.89]; $\mathrm{p}=0.0019$; median OS 11.9 versus 9.6 months, respectively) in patients who had stable disease after the first-line chemotherapy $(n=487$, 
55\%). ${ }^{28}$ However, no significant difference in OS was observed in the patients who had complete/partial response $(n=394,44 \%)(H R=0.94$ [95\% CI 0.74-1.20]; $p=0.6181$; median OS 12.5 versus 12.0 months in the erlotinib and placebo groups, respectively). ${ }^{28}$ The ATLAS trial, which evaluated the benefit of addition of erlotinib to bevacizumab as maintenance therapy after first-line platinum doublet chemotherapy plus bevacizumab, also met its primary end point of improving PFS [4.76 months versus 3.75 months (HR=0.72, $\mathrm{p}=0.0012)] .{ }^{26-27}$ The phase III SWOG-S0023 study which prospectively evaluated maintenance gefitinib after chemo-radiotherapy in unselected patients with locally advanced NSCLC was suspended before completing its target accrual after an unplanned interim analysis showed inferior overall survival in the gefitinib arm compared with the placebo arm (HR $0.633 ; 95 \%$ CI, 0.44 to $0.91 ; P=.013$ ). ${ }^{29}$

Based on the results of BR.21 and SATURN trials, erlotinib (150 mg) was approved by the U.S. FDA as monotherapy in locally advanced or metastatic NSCLC after failure of at least one prior chemotherapy regimen and as maintenance for patients whose disease has not progressed after four cycles of platinum-based first-line chemotherapy.

\section{Predictors of response to EGFR-tyrosine kinase inhibitors}

Early trials of EGFR-tyrosine kinase inhibitors in NSCLC identified the following features: female sex, adenocarcinoma histology, East Asian descent and no prior history of smoking to correlate with response to treatment. ${ }^{8-9,15-16}$ Since then, several EGFR related biomarkers including EGFR mutation, gene copy number and protein expression have been investigated in major clinical trials for their predictive value. EGFR activating mutations, which are found more frequently in patients with the above clinco-pathologic features, have emerged as the strongest predictor of response rates and PFS in patients treated with EGFRtyrosine kinase inhibitors. ${ }^{21,30-32}$ EGFR activating mutations are found in the kinase domain of EGFR gene and comprise mostly in-frame deletions of exon 19 and L858R substitution in exon $21.30-31,33-35$ In unselected NSCLC patients, EGFR mutations are found in about $10 \%$ of the population. In clinico-pathologically selected patients, the incidence is about $60 \%$ in Asians and $40 \%$ in whites.

Despite the strong correlation of clinico-pathologic criteria and EGFR mutations, several recent reports show that EGFR mutations rather than clinico-pathologic criteria should be used to select chemo-naive patients for EGFR-tyrosine kinase inhibitor use. In the IPASS trial, patients with EGFR mutations who were treated with gefitinib had remarkably high ORR (71.2\%), PFS (HR 0.48; 95\% CI, 0.36- 0.64; p<0.001) and improvement in quality of life. In contrast, patients with wild-type EGFR $(n=176)$, treated with gefitinib had inferior ORR (1.1\%), PFS (HR 2.85; 95\% CI, 2.05- 3.98; p<0.001) and OS (HR 1.38; 95\%CI,0.922.09 ; p NS). ${ }^{17}$ The OS disadvantage of EGFR wild type patients who were treated with gefitinib, although not statistically significant, persisted in updated survival analysis and was also observed in the First-SIGNAL study (HR,1.199;95\%CI,0.570-2.521;p=0.632). ${ }^{19},{ }^{21} \mathrm{~A}$ differential response to EGFR-tyrosine kinase inhibitors based on the type of EGFR mutation was noted in some studies ${ }^{17,36}$ although this could not be confirmed in others. ${ }^{18}$

\section{Practical considerations}

Toxicities-The most common adverse reactions with EGFR-tyrosine kinase inhibitors are rash-like events and diarrhea. ${ }^{37-38}$ Erlotinib and gefitinib have similar toxicity profiles, but erlotinib is more toxic as its recommended dose is closer to the maximum tolerated dose. In the BR.21 trial, grade 3/4 rash occurred in 9\% patients with a median time to onset of 8 days. ${ }^{16} \mathrm{~A}$ spectrum of skin, hair and nail changes are known to occur, but the most common dermatologic manifestation is a papulo-pustular rash involving the face and/or upper trunk. On initiation of EGFR-tyrosine kinase inhibitor, all patients should be advised to use 
emollients, minimize sun exposure and use sunscreens. Once skin toxicity is manifest, depending on the severity, topical or systemic glucocorticoids, antibiotics and immunomodulators may be used. ${ }^{39}$ Several expert groups have issued guidelines for grading and management of skin changes related to EGFR inhibition. ${ }^{40-42}$ In the BR.21 trial, grade $3 / 4$ diarrhea occurred in $6 \%$ patients with a median time to onset of 12 days. ${ }^{16}$ Diarrhea is often mild and loperamide may be used for symptomatic management. Most cases of rash and diarrhea are best addressed by symptomatic management and do not necessitate alteration in the course of treatment. However, in case of severe symptoms, dose modifications or treatment interruption may be necessary. In the BR.21 study, $6 \%$ and $1 \%$ of patients needed dose reduction for rash and diarrhea, respectively and each resulted in discontinuation of erlotinib in $1 \%$ of patients. ${ }^{16}$

Interstitial Lung Disease (ILD)-like events have been observed in patients receiving EGFR TKI's, with an overall incidence of about $1 \%$ and a higher incidence in Japanese patients. A prospective study of Japanese patients receiving either gefitinib or chemotherapy, identified older age ( $\geq 55$ ), poor performance status, smoking, short duration since diagnosis of NSCLC, reduced normal lung on CT scan, preexisting chronic ILD, and concurrent cardiac disease as risk factors for development of ILD. ${ }^{43}$ Patients often present with acute onset of dyspnea, sometimes associated with cough or low grade fever, often becoming severe within a short time. These symptoms warrant immediate interruption of EGFR TKI and institution of supportive measures including oxygen, corticosteroids, or assisted ventilation. ${ }^{37-38}$

Dosing-Erlotinib is used at its maximum tolerated dose (MTD) of $150 \mathrm{mg}$, on an empty stomach at least one hour before or two hours after the ingestion of food. When dose reduction is necessary, the erlotinib dose should be reduced in $50 \mathrm{mg}$ decrements. Gefitinib is used at $250 \mathrm{mg}$ day with or without food, a dose lower than its MTD, based on phase II data which showed similar efficacy, but less toxicities with $250 \mathrm{mg} .{ }^{37-38}$

Interactions-Drugs that alter the $\mathrm{pH}$ of the upper gastrointestinal (GI) tract may alter the solubility of erlotinib and gefitinib, thus reducing their bioavailability. Co-administration with omeprazole, a proton pump inhibitor, decreased erlotinib exposure by $46 \%$. Since proton pump inhibitors affect $\mathrm{pH}$ of upper GI tract for an extended period, separation of doses may not eliminate the interaction and hence concomitant use of proton pump inhibitors with erlotinib should be avoided, if possible. If patients need to be treated with an H2-receptor antagonist (e.g. ranitidine), it should be used in a staggered manner: erlotinib must be taken 10 hours after and at least 2 hours before a dose of $\mathrm{H} 2$-receptor antagonist. Erlotinib and gefitinib undergo extensive hepatic metabolism, predominantly by cytochrome P (CYP)3A4. Inhibitors (e.g. ketoconazole) and inducers (e.g. rifampicin) of CYP3A4 would be expected increase and decrease drug exposure respectively. ${ }^{37-38}$ Cigarette smoking, which is known to induce many hepatic CYP450 enzymes, reduces erlotinib exposure and patients should be advised to stop smoking. ${ }^{44}$

Monitoring-Patients with hepatic impairment should be closely monitored during therapy with erlotinib and gefitinib. Dosing should be interrupted or discontinued if total bilirubin is $>3 \times$ upper limit of normal (ULN) and/or transaminases are $>5 \times$ ULN in the setting of normal pretreatment values. ${ }^{37-38}$

Duration-Treatment should continue until disease progression or unacceptable toxicity occurs. Although accelerated progression of disease after discontinuation of TKI has been observed in some studies, ${ }^{45-46}$ there is no evidence at this time that treatment beyond progression is beneficial. 
Erlotinib versus gefitinib-As discussed above, erlotinib is dosed at its MTD, while gefitinib is not and the area under the curve (AUC) of erlotinib at the standard dose is seven times larger than that of gefitinib. In trials which compared first-line conventional chemotherapy with EGFR TKI, response rates of EGFR-mutation positive patients range between $58 \%-83 \%^{20,22}$ and $62.1 \%-73.7 \%^{5,17-18}$ respectively, for erlotinib and gefitinib. PFS ranges for the same patient sub-groups are 9.7-14 months and 9.5-10.8 months respectively. However, these trials differ in terms of populations studied and sensitivity of mutational testing used. At this time, lack of direct comparisons between erlotinib and gefitinib in similar clinical scenarios preclude definitive determination of superiority of one agent over the other.

First line versus second line treatment-Based on available data, it is not entirely clear if the order of use of EGFR TKI is significant. In the NEJ002 trial, 95\% of the patients who received first-line carboplatin-paclitaxel crossed over to gefitinib upon progression. Response rates and median OS in these patients were worse compared with patients who received first-line gefitinib (58.5\% versus. $73.7 \%$ and 30.5 months versus. 23.6 months respectively), indicating that gefitinib may be more effective as first line therapy than as second-line or later therapy. ${ }^{5}$ However, a Spanish Lung Cancer Group study found no difference in OS between first- and second-line treatments with erlotinib in patients with EGFR-mutant tumors. ${ }^{30}$

\section{EGFR-tyrosine kinase inhibitor resistance}

NSCLC patients with sensitizing mutations of EGFR who initially respond to gefitinib or erlotinib ultimately relapse. Primary resistance to EGFR inhibition is caused by mutations of ERBB family of genes that render them insensitive to EGFR-tyrosine kinase inhibition (eg: insertion mutations in exon 20 of EGFR and HER2) ${ }^{47}$ or mutations in a non ERBB gene (eg: PIK3CA, KRAS) ${ }^{48}$ which results in EGFR independent activation of downstream signaling pathways. There are two main mechanisms of secondary resistance: secondary mutations and activation of parallel pathways resulting in alternative mechanisms of activation of downstream targets. The most common causes of secondary resistance are threonine-tomethionine amino acid change at position 790 (T790M) of EGFR kinase domain (found in $50 \%$ of cases) ${ }^{49-50}$ and MET amplification (found in up to $20 \%$ cases).$^{51-52}$ Other proposed mechanisms of EGFR tyrosine kinase inhibitor resistance include signaling via redundant tyrosine kinase receptors (eg: IGF-1R), ${ }^{53}$ constitutive activation of downstream mediators (eg; mutational loss of PTEN phosphatase function leading to Akt activation) ${ }^{54}$ ligand independent activation of EGFR, bypassing cellular EGFR dependence through epithelialto-mesenchymal-like transition, ${ }^{55}$ altered receptor trafficking and efflux of the drug from the cell. ${ }^{56}$

Commonly employed strategies aimed at overcoming EGFR-tyrosine kinase inhibitor resistance are to: 1) irreversibly inhibit EGFR tyrosine kinase by covalent cross-linking of receptors 2) broaden the receptor tyrosine kinase targets of the drug using multi-kinase inhibitors 3) target downstream PI3K or STAT5 pathways 4) target a combination of pathways or 5) target mutant EGFR for degradation. ${ }^{57}$

Lapatinib is an oral, reversible tyrosine kinase inhibitor that targets HER2 in addition to EGFR. In a randomized, open-label, multicenter, phase 2 study lapatinib showed minimal single agent response rates in patients with locally advanced or metastatic NSCLC. ${ }^{58}$ PanERBB inhibitors improve the efficacy of ERBB -targeted therapies by interfering with the co-operation that exists between the receptors. ${ }^{59}$ Dacomitinib (PF00299804) is an irreversible pan-ERBB inhibitor, which in pre-clinical studies was effective against NSCLCs harboring wild-type and mutant EGFR as well as EGFR T790M mutations. ${ }^{60-61}$ In pre- 
treated NSCLC patients, a phase II study demonstrated a significant PFS advantage of dacomitinib over erlotinib, with benefit extending to several subgroups including the EGFR wild type tumors. ${ }^{62}$ In the first line setting, a phase II study in patients clinically enriched for EGFR mutation or had an EGFR mutation reported an encouraging $85 \%$ of EGFR-mutated patients and $57 \%$ of all patients treated with dacomitinib remaining progression-free at 9 months. The disease control rate was $86 \%$ in the entire study group and $94 \%$ in patients with EGFR mutant tumors. ${ }^{63}$ Treatment-related adverse events commonly seen were diarrhea, acne, rash and mucositis. Dacomitinib is being evaluated in a phase III trial in patients who have failed standard therapy and also in several other trials across lines of therapies and a range of histologies and molecular subtypes.

Afatinib (BIBW 2992) is a highly selective, potent, and irreversible inhibitor of both EGFR and HER2 kinases, which overcame T790M-mediated resistance in preclinical lung cancer models. ${ }^{64} \mathrm{~A}$ phase IIb/III trial (LUX-Lung 1 trial) failed to demonstrate improvement in overall survival (primary end-point) with afatinib compared to placebo in over 580 patients with advanced NSCLC who had disease progression after chemotherapy and a firstgeneration EGFR-tyrosine kinase inhibitor. However in a subset of patients who were most likely to have an EGFR mutation based on clinical criteria, improvement in PFS was observed (4.4 months vs. 1.0 month for placebo). Afatinib is being investigated in first-line therapy of EGFR mutant NSCLC and after first generation EGFR-tyrosine kinase inhibitor failure.

Focal EGFR T790M amplification, at least partly due to selection of a pre-existing EGFR T790M-amplified clone can lead to resistance to irreversible pan- ERBB inhibitors. ${ }^{65}$ As with first generation EGFR tyrosine kinase inhibition, T790M mutation may interfere with the efficacy of irreversible pan-ERBB inhibitors also by disrupting the initial reversible binding of these inhibitors to the ATP binding site and thus delaying covalent bond formation. ${ }^{66}$ Moreover, irreversible EGFR inhibitors can overcome T790M resistance only at supra-pharmacologic concentrations. ${ }^{67}$ At such doses concurrent inhibition of wild type EGFR results in skin rash and diarrhea, and limits the ability to achieve plasma concentrations sufficient to inhibit EGFR T790M.

\section{ANAPLASTIC LYMPHOMA KINASE TYROSINE KINASE INHIBITORS}

EML4- ALK translocation was first identified as a 'driver mutation' of lung carcinogenesis in 2007. ${ }^{68}$ ALK and EML4 are both located in the short arm of chromosome 2 separated by $12 \mathrm{Mb}$ and are oriented in opposite $5^{\prime}$ to $3^{\prime}$ directions. EML4-ALK translocation results from a small inversion within chromosome $2 \mathrm{p}$ [inv (2)(p21p23)], which leads to fusion of the $\mathrm{N}$-terminal portion of the protein encoded by the echinoderm microtubule-associated protein-like 4 (EML4) gene with the intracellular signaling portion of the receptor tyrosine kinase encoded by the anaplastic lymphoma kinase (ALK) gene. The chimeric protein, EML4-ALK possesses potent oncogenic activity both in vitro and in vivo. ${ }^{68-70}$ Inhibition of ALK leads to apoptosis in vitro and decreased tumor burden and improved survival in transgenic mouse model that expressed EML4-ALK in lung alveolar epithelial cells. ${ }^{69,71}$

Depending on patient ethnicity and enrichment criteria used, the frequency of EML4-ALK in patients with NSCLC varies between 1 to 13\%. The typical phenotype of a patient with EML4-ALK translocation is that of a young, never or light ( $<10$ pack-years) smoker. EML4ALK positive tumors are more likely advanced stage adenocarcinomas, predominantly the signet ring cell subtype in Western cohorts and acinar subtype in the Asian population. NSCLC patients with EML4-ALK translocations share several clinical characteristics with patients harboring EGFR mutant tumors including never/light smoking history and adenocarcinoma histology, but differ in its increased frequency in men, younger age group 
which is involved and histologic characteristics. However there is a near complete lack of overlap of EML4-ALK translocation and EGFR mutation in the same tumor. Among patients with NSCLC who have clinical characteristics associated with EGFR mutation but who have negative EGFR testing, as many as one in three patients may harbor EML4ALK. ${ }^{68-70,72-74}$

Multiple EML4-ALK variants result from fusion of the variably truncated EML4 to the ALK gene starting at a portion encoded by exon 20. Most of the EML4-ALK variants retain the transforming potential, but clinical implications of the different variants are not known. ${ }^{69-70,74}$ Translocations involving non-EML4 fusion partners (e.g. TFG and KIF5B) have also been described. The non-EML4 fusion partners for ALK may have implications in the diagnostic modality used in detection of ALK translocated NSCLC, but their functional significance is not defined. ${ }^{70}$

\section{Clinical trials of anaplastic lymphoma kinase tyrosine kinase inhibitors}

Crizotinib is an orally bioavailable, selective small-molecule inhibitor of the catalytic activity of c-Met kinase and the ALK fusion protein. ${ }^{75}$ In a phase I study, Kwak et al identified 82 patients with advanced NSCLC from approximately 1500 patients. ${ }^{76}$ After a mean treatment duration of 6.4 months, the overall response rate was $57 \%$ including one confirmed complete response. $33 \%$ patients had stable disease, and the estimated probability of 6-month PFS was $72 \%$. Updated data with 199 patients showed a response rate of $61 \%{ }^{77}$ The response to treatment was exclusive to patients with ALK translocations as demonstrated by lack of response in patients without ALK translocation who were treated in the dose escalation phase. ${ }^{76}$ In preliminary results of a phase III study $(n=136), 53 \%$ response rates were seen in the 76 evaluable patients. ${ }^{78}$ In patients with ALK-translocation positive NSCLC, treatment with crizotinib was associated with a higher OS than that of historical, crizotinib-naïve controls. One year OS was $71 \%$ in patients who received crizotinib as second or third-line therapy in the phase I study, compared with $46 \%$ for those who did not. ${ }^{79}$ Based on response rates observed in these two studies, ${ }^{77-78}$ crizotinib was granted accelerated approval by U.S. FDA for treatment of patients with locally advanced or metastatic NSCLC that is ALK-positive. Further well-controlled clinical trials are needed to verify and describe clinical benefit. In ALK gene-rearranged NSCLC patients, ongoing phase III trials are evaluating crizotinib in first line where it is being compared with platinum-based chemotherapy (pemetrexed and cisplatin or carboplatin) and in second-line with pemetrexed or docetaxel.

Despite the initial responses, the median PFS of patients who received crizotinib in the phase I trial was limited to 10 months. In a model of acquired resistance to crizotinib, established by exposing a highly sensitive EML4-ALK-positive NSCLC cell line to increasing doses of crizotinib, cells resistant to intermediate doses of crizotinib developed amplification of EML4-ALK gene. Cells resistant to higher doses of crizotinib also developed a gatekeeper mutation, L1196M, within the kinase domain, rendering EML4ALK insensitive to crizotinib. ${ }^{80}$ Other mechanisms of acquired resistance which have been described include concurrent co-activation of EGFR signaling. ${ }^{80-82}$

\section{Practical considerations}

Testing technique-Concurrent with its approval of crizotinib, FDA approved the Vysis ALK Break-Apart FISH Probe Kit (Abbott Molecular, Inc.) to detect ALK rearrangements. The break-apart FISH assay detects disruption of the ALK locus but does not confirm EML4 as the partner fusion gene. 
Dosage and interactions-The recommended daily dose of crizotinib is $250 \mathrm{mg}$ taken orally twice daily with or without food. Dosing interruption and/or dose reduction to $200 \mathrm{mg}$ taken orally twice daily may be required based on individual safety and tolerability, then to $250 \mathrm{mg}$ taken orally once daily if further reduction is necessary. ${ }^{83}$ Crizotinib is predominantly metabolized by CYP3A $4 / 5$ and hence concurrent use of strong CYP3A inhibitors and inducers should be avoided. ${ }^{83}$

Toxicities-The most commonly reported adverse events with crizotinib are nausea, diarrhea, vomiting, edema, and constipation. ${ }^{76,83}$ Visual disturbances, noticed especially during changes in ambient lighting from dark to light were reported by $62 \%$ of patients in clinical trials. ${ }^{83}$ The spectrum of disorders described include visual impairment, photopsia, vision blurred, vitreous floaters, photophobia, and diplopia. ${ }^{83}$ Visual symptoms usually started within two weeks of drug administration and improved with continued treatment. Ophthalmological evaluation is recommended, particularly if patients experience photopsia or experience new or increased vitreous floaters. Grade 3 elevations in alanine aminotransferase and aspartate aminotransferase were observed respectively in 5\% and 6\% of patients, with onset during cycle 2 . These were reversible with temporary interruption of crizotinib and in most cases, restarting crizotinib at a lower dose was well tolerated. Severe, life-threatening treatment-related pneumonitis has been reported in $1.6 \%$ of patients treated with crizotinib in clinical trials and close monitoring for pulmonary symptoms is recommended ${ }^{83}$ In patients who have a history of or predisposition for QTc prolongation, or who are taking medications that are known to prolong the QT interval, periodic monitoring with electrocardiograms and electrolytes should be considered. ${ }^{83}$

\section{MET/HGF INHIBITORS}

The c-Met gene located on chromosome 7, encodes a receptor tyrosine kinase, whose only known high-affinity ligand is hepatocyte growth factor (HGF). High levels of intra-tumoral c-Met expression in NSCLC have been identified as a poor prognostic indicator and have been implicated in poor response to upfront EGFR inhibition, EGFR-tyrosine kinase resistance and propensity for metastasis. In untreated NSCLC, c-Met amplification occurs in $3 \%$ cases, but is seen in up to $22 \%$ of EGFR mutant tumors with acquired resistance to EGFR TKIs. ${ }^{51-52,84-85}$

Therapeutic strategies used for targeted MET inhibition include small interfering RNA, small molecules, and specific monoclonal antibodies. ${ }^{86}$ ARQ197, a highly selective, orally administered MET inhibitor binds to a region of MET outside of the ATP binding site and impairs kinase activation allosterically. In a phase 2 study, ARQ197 in combination with erlotinib improved PFS (median 16.1 weeks versus. 9.7 weeks: HR 0.81 [95\% CI 0.57, 1.15]; $\mathrm{p}=0.23$ ) compared to erlotinib alone in second/third-line EGFR-inhibitor naive NSCLC 87 A pre-specified analysis adjusting for prognostic factors yielded PFS HR 0.68 ( $95 \%$ CI $0.47,0.98 ; p<0.05$ ) with improved benefit noted in subgroups of patients with nonsquamous histology, K-RAS mutations, and EGFR wild-type status. ${ }^{87}$ An ongoing phase 3 trial is evaluating ARQ 197 with erlotinib in patients with advanced non-squamous NSCLC who have received 1 or 2 prior lines of therapy. Cabozantinib (XL184) is an oral, ATPcompetitive small molecule inhibitor of multiple kinases, in particular MET and VEGFR. Preliminary results from a randomized phase 2 discontinuation study suggest single agent activity of XL184 in patients with advanced NSCLC who failed multiple prior systemic therapies, with overall disease control rate of $50 \%{ }^{88} \mathrm{XL} 184$ is being evaluated in combination with erlotinib in NSCLC patients who have progressive disease after initial response to erlotinib. Crizotinib, is also a potent inhibitor of MET. 


\section{VASCULAR ENDOTHELIAL GROWTH FACTOR RECEPTOR TYROSINE KINASE INHIBITORS}

Vascular endothelial growth factor (VEGF), a mitogen specific for vascular endothelial cells, plays a key role in angiogenesis. VEGF-related angiogenic signal is mediated by kinase domain receptor (KDR) and Fms-like tyrosine kinase (Flt-1), which have intracellular tyrosine kinase activity. Vandetanib (targets VEGFR-2 and 3, RET and EGFR tyrosine kinases), sunitinib (targets VEGFR1/2/3, FLT PDGFR-b, c-kit), cediranib (targets VEGFR1/2/3 PDGFR-b, c-kit) and axitinib (targets VEGFR1/2/3, PDGFR-a, c-kit) are orally active small molecule inhibitors which target VEGF family of tyrosine kinases and a wide spectrum of other tyrosine kinase receptors. Table 1 summarizes important phase II/III clinical trial data on these multi-kinase inhibitors in NSCLC. ${ }^{89-95}$ Despite strong preclinical rationale, the lack of reliable prognostic or predictive markers for selecting patients who would benefit from antiangiogenic therapy has hampered the clinical development of these agents. Although several potential angiogenic biomarkers (e.g. microvessel density, vascular endothelial growth factor, vascular endothelial growth factor receptors) have been extensively studied, no definitive marker has been identified to date. Hence patient selection for angiogenesis inhibitors is currently limited to clinical and/or histological features. ${ }^{96}$

\section{SUMMARY}

Identification of novel tyrosine kinase targets and clinical development of its inhibitors have ushered in an era of personalized care in non-small cell lung cancer. The lessons learned in the development of first-generation EGFR-tyrosine kinase inhibitors have led to shortening of time between understanding the biology, clinico-pathologic features of the patients, and development of diagnostic tests, drug development, and identification of resistance mechanisms. ${ }^{97}$ Ongoing efforts are focused on overcoming resistance mechanisms of existing targets, identification of novel targets and biomarkers.

\section{Acknowledgments}

Funding support: Intramural Research Program, National Cancer Institute

\section{REFERENCES}

1. Goldstraw P, Crowley J, Chansky K, et al. The IASLC Lung Cancer Staging Project: proposals for the revision of the TNM stage groupings in the forthcoming (seventh) edition of the TNM Classification of malignant tumours. J Thorac Oncol. 2007 Aug; 2(8):706-714. [PubMed: 17762336]

2. Jemal A, Siegel R, Xu J, Ward E. Cancer statistics, 2010. CA Cancer J Clin. 2010 Sep-Oct;60(5): 277-300. [PubMed: 20610543]

3. Chemotherapy in non-small cell lung cancer: a meta-analysis using updated data on individual patients from 52 randomised clinical trials. Non-small Cell Lung Cancer Collaborative Group. BMJ. 1995 Oct 7; 311(7010):899-909. [PubMed: 7580546]

4. [Accessed September 21, 2011] Cancer Incidence - Surveillance, Epidemiology, and End Results (SEER) Registries Research Data. 2011 Apr 15. http://seer.cancer.gov 2011

5. Maemondo M, Inoue A, Kobayashi K, et al. Gefitinib or chemotherapy for non-small-cell lung cancer with mutated EGFR. N Engl J Med. 2010 Jun 24; 362(25):2380-2388. [PubMed: 20573926]

6. Hynes NE, Lane HA. ERBB receptors and cancer: the complexity of targeted inhibitors. Nat Rev Cancer. 2005 May; 5(5):341-354. [PubMed: 15864276]

7. Citri A, Yarden Y. EGF-ERBB signalling: towards the systems level. Nat Rev Mol Cell Biol. 2006 Jul; 7(7):505-516. [PubMed: 16829981] 
8. Kris MG, Natale RB, Herbst RS, et al. Efficacy of gefitinib, an inhibitor of the epidermal growth factor receptor tyrosine kinase, in symptomatic patients with non-small cell lung cancer: a randomized trial. JAMA. 2003 Oct 22; 290(16):2149-2158. [PubMed: 14570950]

9. Fukuoka M, Yano S, Giaccone G, et al. Multi-institutional randomized phase II trial of gefitinib for previously treated patients with advanced non-small-cell lung cancer (The IDEAL 1 Trial) [corrected]. J Clin Oncol. 2003 Jun 15; 21(12):2237-2246. [PubMed: 12748244]

10. Perez-Soler R. Phase II clinical trial data with the epidermal growth factor receptor tyrosine kinase inhibitor erlotinib (OSI-774) in non-small-cell lung cancer. Clin Lung Cancer. 2004 Dec; 6(Suppl 1):S20-S23. [PubMed: 15638953]

11. Giaccone G, Herbst RS, Manegold C, et al. Gefitinib in combination with gemcitabine and cisplatin in advanced non-small-cell lung cancer: a phase III trial--INTACT 1. J Clin Oncol. 2004 Mar 1; 22(5):777-784. [PubMed: 14990632]

12. Herbst RS, Giaccone G, Schiller JH, et al. Gefitinib in combination with paclitaxel and carboplatin in advanced non-small-cell lung cancer: a phase III trial--INTACT 2. J Clin Oncol. 2004 Mar 1; 22(5):785-794. [PubMed: 14990633]

13. Gatzemeier U, Pluzanska A, Szczesna A, et al. Phase III study of erlotinib in combination with cisplatin and gemcitabine in advanced non-small-cell lung cancer: the Tarceva Lung Cancer Investigation Trial. J Clin Oncol. 2007 Apr 20; 25(12):1545-1552. [PubMed: 17442998]

14. Herbst RS, Prager D, Hermann R, et al. TRIBUTE: a phase III trial of erlotinib hydrochloride (OSI-774) combined with carboplatin and paclitaxel chemotherapy in advanced non-small-cell lung cancer. J Clin Oncol. 2005 Sep 1; 23(25):5892-5899. [PubMed: 16043829]

15. Thatcher N, Chang A, Parikh P, et al. Gefitinib plus best supportive care in previously treated patients with refractory advanced non-small-cell lung cancer: results from a randomised, placebocontrolled, multicentre study (Iressa Survival Evaluation in Lung Cancer). Lancet. 2005 Oct-Nov; 366(9496):1527-1537. [PubMed: 16257339]

16. Shepherd FA, Rodrigues Pereira J, Ciuleanu T, et al. Erlotinib in previously treated non-small-cell lung cancer. N Engl J Med. 2005 Jul 14; 353(2):123-132. [PubMed: 16014882]

17. Mok TS, Wu YL, Thongprasert S, et al. Gefitinib or carboplatin-paclitaxel in pulmonary adenocarcinoma. N Engl J Med. 2009 Sep 3; 361(10):947-957. [PubMed: 19692680]

18. Mitsudomi T, Morita S, Yatabe Y, et al. Gefitinib versus cisplatin plus docetaxel in patients with non-small-cell lung cancer harbouring mutations of the epidermal growth factor receptor (WJTOG3405): an open label, randomised phase 3 trial. Lancet Oncol. 2010 Feb; 11(2):121-128. [PubMed: 20022809]

19. Lee, DHHJY.; Yu, SY., et al. A randomized phase III study of gefitinib (IRESSA) versus standard chemotherapy (gemcitabine plus cisplatin) as a first-line treatment for never-smokers with advanced or metastatic adenocarcinoma of the lung; Presented at World conference on lung Cancer; 2009.

20. Zhou C, Wu YL, Chen G, et al. Erlotinib versus chemotherapy as first-line treatment for patients with advanced EGFR mutation-positive non-small-cell lung cancer (OPTIMAL, CTONG-0802): a multicentre, open-label, randomised, phase 3 study. Lancet Oncol. 2011 Aug; 12(8):735-742. [PubMed: 21783417]

21. Fukuoka M, Wu YL, Thongprasert S, et al. Biomarker Analyses and Final Overall Survival Results From a Phase III, Randomized, Open-Label, First-Line Study of Gefitinib Versus Carboplatin/ Paclitaxel in Clinically Selected Patients With Advanced Non-Small-Cell Lung Cancer in Asia (IPASS). J Clin Oncol. 2011 Jul 20; 29(21):2866-2874. [PubMed: 21670455]

22. Rosell RGR, Vergnenegre A. Erlotinib versus chemotherapy (CT) in advanced non-small cell lung cancer (NSCLC) patients (p) with epidermal growth factor receptor (EGFR) mutations: Interim results of the European Erlotinib Versus Chemotherapy (EURTAC) phase III randomized trial. J Clin Oncol. 2011; 29 ((suppl; abstr 7503)).

23. Takeda K, Hida T, Sato T, et al. Randomized phase III trial of platinum-doublet chemotherapy followed by gefitinib compared with continued platinum-doublet chemotherapy in Japanese patients with advanced non-small-cell lung cancer: results of a west Japan thoracic oncology group trial (WJTOG0203). J Clin Oncol. 2010 Feb 10; 28(5):753-760. [PubMed: 20038730] 
24. Gaafar RMSV, Scagliotti G, et al. A double-blind, randomized, placebo-controlled phase III intergroup study of gefitinib $(\mathrm{G})$ in patients (pts) with advanced NSCLC, non-progressing after first-line platinum-based chemotherapy (EORTC 08021-ILCP 01/03). J Clin Oncol. 2010; 28:15s. (suppl; abstr 7518) 2010.

25. Cappuzzo F, Ciuleanu T, Stelmakh L, et al. Erlotinib as maintenance treatment in advanced nonsmall-cell lung cancer: a multicentre, randomised, placebo-controlled phase 3 study. Lancet Oncol. 2010 Jun; 11(6):521-529. [PubMed: 20493771]

26. Miller VAOCP, Soh C, et al. A randomized, double-blind, placebo-controlled, phase IIIb trial (ATLAS) comparing bevacizumab (B) therapy with or without erlotinib (E) after completion of chemotherapy with B for first-line treatment of locally advanced, recurrent, or metastatic nonsmall cell lung cancer (NSCLC). J Clin Oncol. 2009; 27:18s. (suppl; abstr LBA8002) 2009.

27. Kabbinavar FFMV, Johnson BE, et al. Overall survival (OS) in ATLAS, a phase IIIb trial comparing bevacizumab (B) therapy with or without erlotinib (E) after completion of chemotherapy (chemo) with B for first-line treatment of locally advanced, recurrent, or metastatic non-small cell lung cancer (NSCLC). J Clin Oncol. 2010; 28:15s. (suppl; abstr 7526) 2010.

28. Coudert B, Ciuleanu T, Park K, et al. Survival benefit with erlotinib maintenance therapy in patients with advanced non-small-cell lung cancer (NSCLC) according to response to first-line chemotherapy. Ann Oncol. 2011 May 24.

29. Kelly K, Chansky K, Gaspar LE, et al. Phase III trial of maintenance gefitinib or placebo after concurrent chemoradiotherapy and docetaxel consolidation in inoperable stage III non-small-cell lung cancer: SWOG S0023. J Clin Oncol. 2008 May 20; 26(15):2450-2456. [PubMed: 18378568]

30. Rosell R, Moran T, Queralt C, et al. Screening for epidermal growth factor receptor mutations in lung cancer. N Engl J Med. 2009 Sep 3; 361(10):958-967. [PubMed: 19692684]

31. Sequist LV, Martins RG, Spigel D, et al. First-line gefitinib in patients with advanced non-smallcell lung cancer harboring somatic EGFR mutations. J Clin Oncol. 2008 May 20; 26(15):24422449. [PubMed: 18458038]

32. Hirsch FR, Varella-Garcia M, Bunn PA Jr, et al. Molecular predictors of outcome with gefitinib in a phase III placebo-controlled study in advanced non-small-cell lung cancer. J Clin Oncol. 2006 Nov 1; 24(31):5034-5042. [PubMed: 17075123]

33. Lynch TJ, Bell DW, Sordella R, et al. Activating mutations in the epidermal growth factor receptor underlying responsiveness of non-small-cell lung cancer to gefitinib. N Engl J Med. 2004 May 20; 350(21):2129-2139. [PubMed: 15118073]

34. Paez JG, Janne PA, Lee JC, et al. EGFR mutations in lung cancer: correlation with clinical response to gefitinib therapy. Science. 2004 Jun 4; 304(5676):1497-1500. [PubMed: 15118125]

35. Pao W, Miller V, Zakowski M, et al. EGF receptor gene mutations are common in lung cancers from "never smokers" and are associated with sensitivity of tumors to gefitinib and erlotinib. Proc Natl Acad Sci U S A. 2004 Sep 7; 101(36):13306-13311. [PubMed: 15329413]

36. Jackman DM, Miller VA, Cioffredi LA, et al. Impact of epidermal growth factor receptor and KRAS mutations on clinical outcomes in previously untreated non-small cell lung cancer patients: results of an online tumor registry of clinical trials. Clin Cancer Res. 2009 Aug 15; 15(16):52675273. [PubMed: 19671843]

37. Tarceva (erlotinib). South San Francisco, CA: Genentech (package insert); http://www.accessdata.fda.gov/drugsatfda_docs/label/2010/021743s14s16lbl.pdf

38. Iressa (gefitinib). Wilmington, DE: AstraZeneca (package insert); http://www1.astrazeneca-us.com/pi/iressa.pdf

39. Lynch TJ Jr, Kim ES, Eaby B, Garey J, West DP, Lacouture ME. Epidermal growth factor receptor inhibitor-associated cutaneous toxicities: an evolving paradigm in clinical management. Oncologist. 2007 May; 12(5):610-621. [PubMed: 17522250]

40. Gridelli C, Maione P, Amoroso D, et al. Clinical significance and treatment of skin rash from erlotinib in non-small cell lung cancer patients: results of an Experts Panel Meeting. Crit Rev Oncol Hematol. 2008 May; 66(2):155-162. [PubMed: 18083041]

41. Potthoff K, Hofheinz R, Hassel JC, et al. Interdisciplinary management of EGFR-inhibitor-induced skin reactions: a German expert opinion. Ann Oncol. 2011 Mar; 22(3):524-535. [PubMed: 20709812] 
42. Lacouture ME, Maitland ML, Segaert S, et al. A proposed EGFR inhibitor dermatologic adverse event-specific grading scale from the MASCC skin toxicity study group. Support Care Cancer. 2010 Apr; 18(4):509-522. [PubMed: 20145956]

43. Kudoh S, Kato H, Nishiwaki Y, et al. Interstitial lung disease in Japanese patients with lung cancer: a cohort and nested case-control study. Am J Respir Crit Care Med. 2008 Jun 15; 177(12): 1348-1357. [PubMed: 18337594]

44. Li J, Zhao M, He P, Hidalgo M, Baker SD. Differential metabolism of gefitinib and erlotinib by human cytochrome P450 enzymes. Clin Cancer Res. 2007 Jun 15; 13(12):3731-3737. [PubMed: 17575239]

45. Riely GJ, Kris MG, Zhao B, et al. Prospective assessment of discontinuation and reinitiation of erlotinib or gefitinib in patients with acquired resistance to erlotinib or gefitinib followed by the addition of everolimus. Clin Cancer Res. 2007 Sep 1; 13(17):5150-5155. [PubMed: 17785570]

46. Chaft JE, Oxnard GR, Sima CS, Miller VA, Kris MG, Riely GJ. Disease flare after tyrosine kinase inhibitor discontinuation in patients with EGFR-mutant lung cancer and acquired resistance to erlotinib or gefitinib. Clin Cancer Res. 2011 Aug 19.

47. Greulich H, Chen TH, Feng W, et al. Oncogenic transformation by inhibitor-sensitive and resistant EGFR mutants. PLoS Med. 2005 Nov.2(11):e313. [PubMed: 16187797]

48. Pao W, Wang TY, Riely GJ, et al. KRAS mutations and primary resistance of lung adenocarcinomas to gefitinib or erlotinib. PLoS Med. 2005 Jan.2(1):e17. [PubMed: 15696205]

49. Kobayashi S, Boggon TJ, Dayaram T, et al. EGFR mutation and resistance of non-small-cell lung cancer to gefitinib. N Engl J Med. 2005 Feb 24; 352(8):786-792. [PubMed: 15728811]

50. Pao W, Miller VA, Politi KA, et al. Acquired resistance of lung adenocarcinomas to gefitinib or erlotinib is associated with a second mutation in the EGFR kinase domain. PLoS Med. 2005 Mar. 2(3):e73. [PubMed: 15737014]

51. Bean J, Brennan C, Shih JY, et al. MET amplification occurs with or without T790M mutations in EGFR mutant lung tumors with acquired resistance to gefitinib or erlotinib. Proc Natl Acad Sci U S A. 2007 Dec 26; 104(52):20932-20937. [PubMed: 18093943]

52. Engelman JA, Zejnullahu K, Mitsudomi T, et al. MET amplification leads to gefitinib resistance in lung cancer by activating ERBB3 signaling. Science. 2007 May 18; 316(5827):1039-1043. [PubMed: 17463250]

53. Gong Y, Yao E, Shen R, et al. High expression levels of total IGF-1R and sensitivity of NSCLC cells in vitro to an anti-IGF-1R antibody (R1507). PLoS One. 2009; 4(10):e7273. [PubMed: 19806209]

54. Sos ML, Koker M, Weir BA, et al. PTEN loss contributes to erlotinib resistance in EGFR-mutant lung cancer by activation of Akt and EGFR. Cancer Res. 2009 Apr 15; 69(8):3256-3261. [PubMed: 19351834]

55. Uramoto H, Iwata T, Onitsuka T, Shimokawa H, Hanagiri T, Oyama T. Epithelial-mesenchymal transition in EGFR-TKI acquired resistant lung adenocarcinoma. Anticancer Res. 2010 Jul; 30(7): 2513-2517. [PubMed: 20682976]

56. Engelman JA, Settleman J. Acquired resistance to tyrosine kinase inhibitors during cancer therapy. Curr Opin Genet Dev. 2008 Feb; 18(1):73-79. [PubMed: 18325754]

57. Rubin BP, Duensing A. Mechanisms of resistance to small molecule kinase inhibition in the treatment of solid tumors. Lab Invest. 2006 Oct; 86(10):981-986. [PubMed: 16924245]

58. Ross HJ, Blumenschein GR Jr, Aisner J, et al. Randomized phase II multicenter trial of two schedules of lapatinib as first- or second-line monotherapy in patients with advanced or metastatic non-small cell lung cancer. Clin Cancer Res. 2010 Mar 15; 16(6):1938-1949. [PubMed: 20215545]

59. Britten CD. Targeting ErbB receptor signaling: a pan-ErbB approach to cancer. Mol Cancer Ther. 2004 Oct; 3(10):1335-1342. [PubMed: 15486201]

60. Engelman JA, Zejnullahu K, Gale CM, et al. PF00299804, an irreversible pan-ERBB inhibitor, is effective in lung cancer models with EGFR and ERBB2 mutations that are resistant to gefitinib. Cancer Res. 2007 Dec 15; 67(24):11924-11932. [PubMed: 18089823] 
61. Gonzales AJ, Hook KE, Althaus IW, et al. Antitumor activity and pharmacokinetic properties of PF-00299804, a second-generation irreversible pan-erbB receptor tyrosine kinase inhibitor. Mol Cancer Ther. 2008 Jul; 7(7):1880-1889. [PubMed: 18606718]

62. Boyer MJBF, Park K, et al. Efficacy and safety of PF299804 versus erlotinib (E): A global, randomized phase II trial in patients (pts) with advanced non-small cell lung cancer (NSCLC) after failure of chemotherapy (CT).

63. Mok TSD, Park K, et al. Efficacy and safety of PF-00299804 (PF299), an oral, irreversible, panhuman epidermal growth factor receptor (pan-HER) tyrosine kinase inhibitor (TKI), as firstline treatment (tx) of selected patients (pts) with advanced (adv) non-small cell lung cancer (NSCLC).

64. Li D, Ambrogio L, Shimamura T, et al. BIBW2992, an irreversible EGFR/HER2 inhibitor highly effective in preclinical lung cancer models. Oncogene. 2008 Aug 7; 27(34):4702-4711. [PubMed: 18408761]

65. Ercan D, Zejnullahu K, Yonesaka K, et al. Amplification of EGFR T790M causes resistance to an irreversible EGFR inhibitor. Oncogene. 2010 Apr 22; 29(16):2346-2356. [PubMed: 20118985]

66. Rauh D, Sos ML, Rode HB, et al. Chemogenomic Profiling Provides Insights into the Limited Activity of Irreversible EGFR Inhibitors in Tumor Cells Expressing the T790M EGFR Resistance Mutation. Cancer Research. 2010 Feb 1; 70(3):868-874. [PubMed: 20103621]

67. Haber DA, Godin-Heymann N, LlIkus L, et al. The T790M "gatekeeper" mutation in EGFR mediates resistance to low concentrations of an irreversible EGFR inhibitor. Mol Cancer Ther. 2008 Apr; 7(4):874-879. [PubMed: 18413800]

68. Soda M, Choi YL, Enomoto M, et al. Identification of the transforming EML4-ALK fusion gene in non-small-cell lung cancer. Nature. 2007 Aug 2; 448(7153):561-566. [PubMed: 17625570]

69. Koivunen JP, Mermel C, Zejnullahu K, et al. EML4-ALK fusion gene and efficacy of an ALK kinase inhibitor in lung cancer. Clin Cancer Res. 2008 Jul 1; 14(13):4275-4283. [PubMed: 18594010]

70. Takeuchi K, Choi YL, Soda M, et al. Multiplex reverse transcription-PCR screening for EML4ALK fusion transcripts. Clin Cancer Res. 2008 Oct 15; 14(20):6618-6624. [PubMed: 18927303]

71. Mano H, Soda M, Takada S, et al. A mouse model for EML4-ALK-positive lung cancer. P Natl Acad Sci USA. 2008 Dec 16; 105(50):19893-19897.

72. Shaw AT, Yeap BY, Mino-Kenudson M, et al. Clinical features and outcome of patients with nonsmall-cell lung cancer who harbor EML4-ALK. J Clin Oncol. 2009 Sep 10; 27(26):4247-4253. [PubMed: 19667264]

73. Rodig SJ, Mino-Kenudson M, Dacic S, et al. Unique clinicopathologic features characterize ALKrearranged lung adenocarcinoma in the western population. Clin Cancer Res. 2009 Aug 15; 15(16):5216-5223. [PubMed: 19671850]

74. Sasaki T, Rodig SJ, Chirieac LR, Janne PA. The biology and treatment of EML4-ALK non-small cell lung cancer. Eur J Cancer. 2010 Jul; 46(10):1773-1780. [PubMed: 20418096]

75. Christensen JG, Zou HY, Arango ME, et al. Cytoreductive antitumor activity of PF-2341066, a novel inhibitor of anaplastic lymphoma kinase and c-Met, in experimental models of anaplastic large-cell lymphoma. Mol Cancer Ther. 2007 Dec; 6(12 Pt 1):3314-3322. [PubMed: 18089725]

76. Kwak EL, Bang YJ, Camidge DR, et al. Anaplastic lymphoma kinase inhibition in non-small-cell lung cancer. N Engl J Med. 2010 Oct 28; 363(18):1693-1703. [PubMed: 20979469]

77. Camidge DRBY, Kwak EL, et al. Progression-free survival (PFS) from a phase I study of crizotinib (PF-02341066) in patients with ALK-positive non-small cell lung cancer (NSCLC). J Clin Oncol. 2011; 29 (suppl; abstr 2501).

78. Crinò LKD, Riely GJ, et al. Initial phase II results with crizotinib in advanced ALK-positive nonsmall cell lung cancer (NSCLC): PROFILE 1005. J Clin Oncol. 2011; 29 (suppl; abstr 7514).

79. Shaw AT, Yeap BY, Solomon BJ, et al. Effect of crizotinib on overall survival in patients with advanced non-small-cell lung cancer harbouring ALK gene rearrangement: a retrospective analysis. Lancet Oncol. 2011 Sep 16.

80. Katayama R, Khan TM, Benes C, et al. Therapeutic strategies to overcome crizotinib resistance in non-small cell lung cancers harboring the fusion oncogene EML4-ALK. Proc Natl Acad Sci U S A. 2011 May 3; 108(18):7535-7540. [PubMed: 21502504] 
81. Sasaki T, Koivunen J, Ogino A, et al. A Novel ALK Secondary Mutation and EGFR Signaling Cause Resistance to ALK Kinase Inhibitors. Cancer Res. 2011 Sep 15; 71(18):6051-6060. [PubMed: 21791641]

82. Choi YL, Soda M, Yamashita Y, et al. EML4-ALK mutations in lung cancer that confer resistance to ALK inhibitors. N Engl J Med. 2010 Oct 28; 363(18):1734-1739. [PubMed: 20979473]

83. Xalkori (crizotinib). San Diego, CA: Pfizer (package insert); http://www.accessdata.fda.gov/drugsatfda_docs/appletter/2011/202570s0001tr.pdf

84. Benedettini E, Sholl LM, Peyton M, et al. Met activation in non-small cell lung cancer is associated with de novo resistance to EGFR inhibitors and the development of brain metastasis. Am J Pathol. 2010 Jul; 177(1):415-423. [PubMed: 20489150]

85. Comoglio PM, Giordano S, Trusolino L. Drug development of MET inhibitors: targeting oncogene addiction and expedience. Nat Rev Drug Discov. 2008 Jun; 7(6):504-516. [PubMed: 18511928]

86. Salgia R, Cipriani NA, Abidoye OO, Vokes E. MET as a target for treatment of chest tumors. Lung Cancer. 2009 Feb; 63(2):169-179. [PubMed: 18672314]

87. Schiller JHAWL, Brugger W, et al. Results from ARQ 197-209: A global randomized placebocontrolled phase II clinical trial of erlotinib plus ARQ 197 versus erlotinib plus placebo in previously treated EGFR inhibitor-naive patients with locally advanced or metastatic non-small cell lung cancer (NSCLC). J Clin Oncol. 2010; 28:18s. (suppl; abstr LBA7502).

88. Yasenchak CNK, Awada A, et al. Phase 2 results of XL184 in a cohort of patients (pts) with advanced non-small cell lung cancer (NSCLC). Ejc Suppl. 2010; 8(7):126.

89. de Boer RH, Arrieta O, Yang CH, et al. Vandetanib plus pemetrexed for the second-line treatment of advanced non-small-cell lung cancer: a randomized, double-blind phase III trial. J Clin Oncol. 2011 Mar 10; 29(8):1067-1074. [PubMed: 21282537]

90. Natale RB, Thongprasert S, Greco FA, et al. Phase III Trial of Vandetanib Compared With Erlotinib in Patients With Previously Treated Advanced Non-Small-Cell Lung Cancer. Journal of Clinical Oncology. 2011 Mar; 29(8):1059-1066. [PubMed: 21282542]

91. Herbst RS, Sun Y, Eberhardt WEE, et al. Vandetanib plus docetaxel versus docetaxel as secondline treatment for patients with advanced non-small-cell lung cancer (ZODIAC): a double-blind, randomised, phase 3 trial. Lancet Oncology. 2010 Jul; 11(7):619-626. [PubMed: 20570559]

92. Lee JHV, Park K, et al. Vandetanib versus placebo in patients with advanced non-small cell lung cancer (NSCLC) after prior therapy with an EGFR tyrosine kinase inhibitor (TKI): A randomized, double-blind phase III trial (ZEPHYR). J Clin Oncol. 2010; 28:15s. (suppl; abstr 7525).

93. Goss GD, Arnold A, Shepherd FA, et al. Randomized, Double-Blind Trial of Carboplatin and Paclitaxel With Either Daily Oral Cediranib or Placebo in Advanced Non-Small-Cell Lung Cancer: NCIC Clinical Trials Group BR24 Study. Journal of Clinical Oncology. 2010 Jan 1; 28(1): 49-55. [PubMed: 19917841]

94. Schiller JH, Larson T, Ou SH, et al. Efficacy and safety of axitinib in patients with advanced nonsmall-cell lung cancer: results from a phase II study. J Clin Oncol. 2009 Aug 10; 27(23):38363841. [PubMed: 19597027]

95. Scagliotti, G. Sunitinib (SU) in combination with erlotinib (E) for the treatment of advanced/ metastatic non-small cell lung cancer (NSCLC): a phase III study. 35th European Society for Medical Oncology (ESMO) Congress; Milan, Italy. 2010. in

96. Salgia R. Prognostic significance of angiogenesis and angiogenic growth factors in nonsmall cell lung cancer. Cancer. 2011 Sep 1; 117(17):3889-3899. [PubMed: 21858799]

97. Gerber DE, Minna JD. ALK inhibition for non-small cell lung cancer: from discovery to therapy in record time. Cancer cell. 2010 Dec 14; 18(6):548-551. [PubMed: 21156280] 


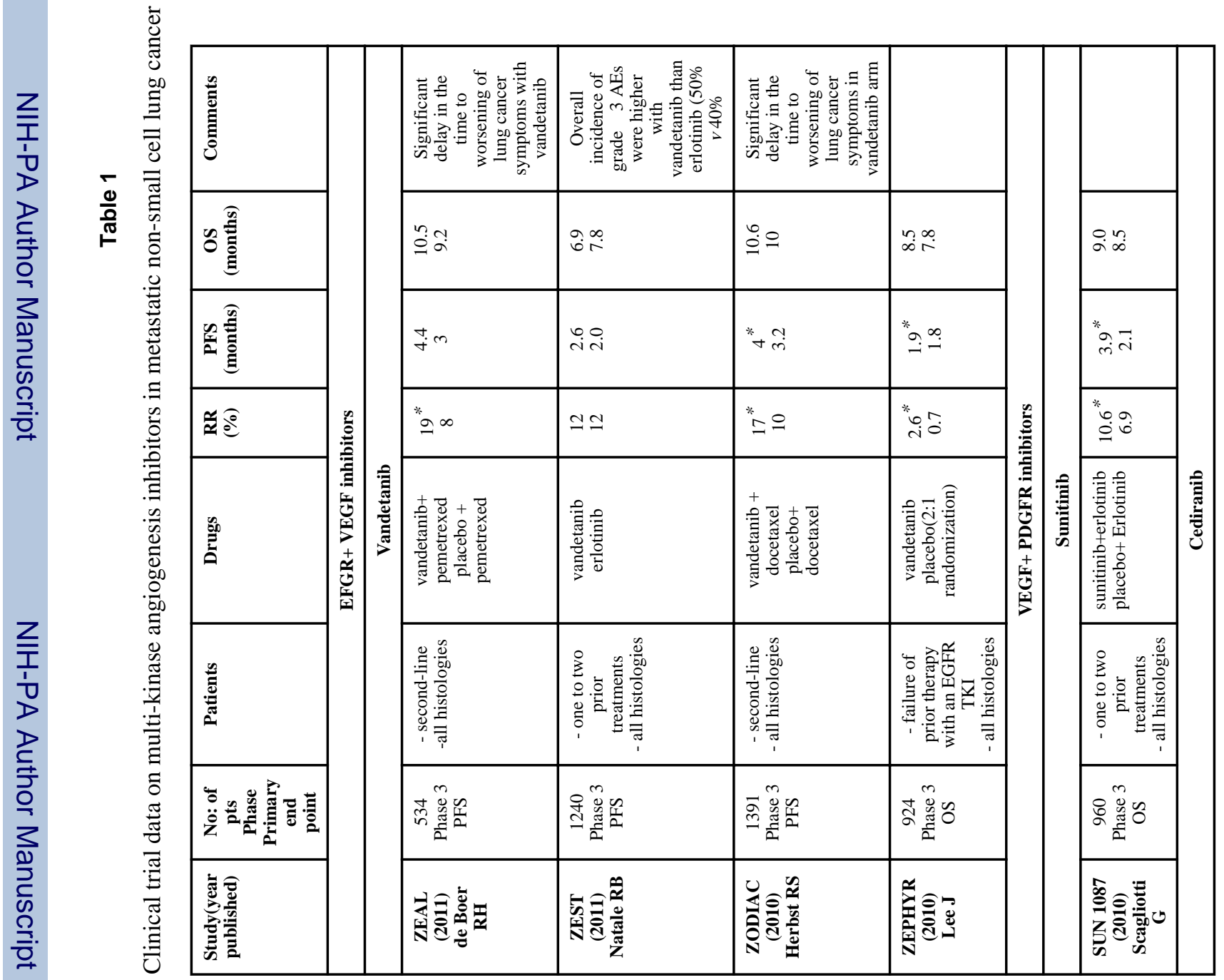




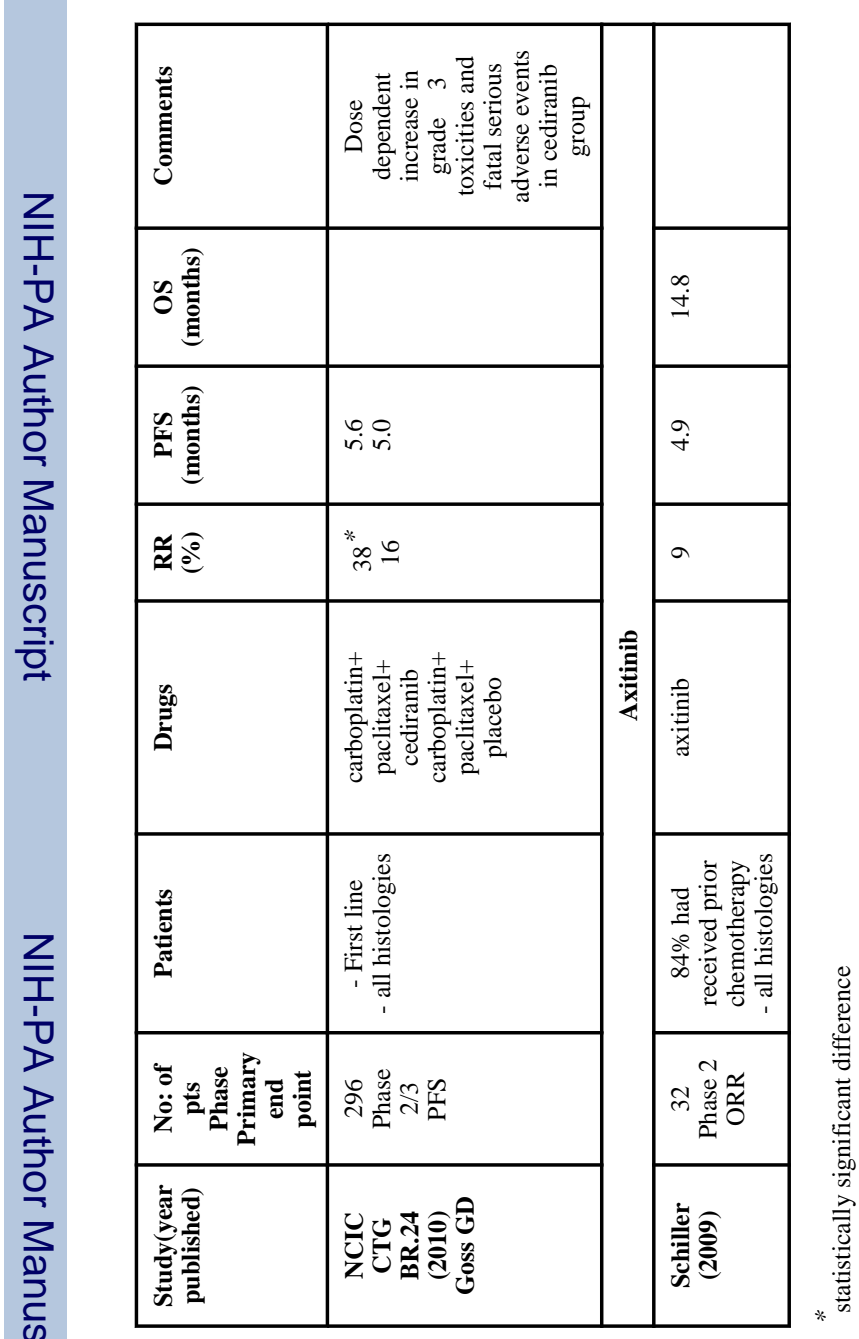

